Arq. Bras. Med. Vet. Zootec., v.63, n.2, p.465-472, 2011

\title{
Resíduo desidratado de cervejaria para suínos em terminação
}

\author{
[Dehydrated residue of brewery for finishing swine] \\ D.M.N. Albuquerque ${ }^{1}$, J.B. Lopes ${ }^{2}$, M.H. Klein Junior ${ }^{2}$, R.R. Merval ${ }^{2}$, \\ F.E.S. Silva ${ }^{2}$, M.P.F. Teixeira ${ }^{2}$ \\ ${ }^{1}$ Agência de Defesa Agropecuária do Piauí, \\ Rua 19 de novembro, 1980 - Teresina - PI \\ ${ }^{2}$ Centro de Ciências Agrárias da Universidade Federal do Piauí - Campus da Socopo \\ 64049-550 - Teresina, PI
}

\begin{abstract}
RESUMO
Determinaram-se os coeficientes de digestibilidade e de metabolizabilidade da matéria seca (MS), da energia bruta (EB), da proteína bruta (PB) e da fibra bruta (FB) e as energias digestível e metabolizável do resíduo desidratado de cervejaria (RDC) para suínos na fase de terminação, e avaliaram-se o desempenho e as características da carcaça desses animais, alimentados com dietas que continham porcentagens de inclusão do RDC - 0, 5, 10, 15 e 20\% -, bem como estudaram-se os parâmetros fisiológicos. No ensaio de digestibilidade, foram utilizados 12 leitões, machos, com média de peso de $57,3 \pm 5,6 \mathrm{~kg}$. Seis deles receberam a ração referência, à base de milho e farelo de soja, e seis a ração teste. No ensaio de desempenho, foram utilizados 40 leitões, com média de peso de $60,8 \pm 1,98 \mathrm{~kg}$. Os coeficientes de digestibilidade aparente da MS, EB, PB e FB foram, respectivamente, de 53,9\%, 73,9\%, $53,3 \%$ e $62,5 \%$, e os valores das energias digestível e metabolizável do RDC de 2.628 e $2.623 \mathrm{kcal} / \mathrm{kg}$, respectivamente. A inclusão de RDC até a proporção de $20 \%$ não influenciou os parâmetros de desempenho e fisiológicos, nem as características de carcaça de suínos em terminação.
\end{abstract}

Palavras-chave: suíno, alimento alternativo, cevada, desempenho, digestibilidade

\begin{abstract}
The digestibility and metabolizability coefficients of the dry matter (DM), gross energy (GE), crude protein $(C P)$, crude fiber (CF), digestible energy (DE) and metabolizable energy (ME) of the dehydrated residue of brewery (DRB) for swine in termination were determined. Performance and carcass characteristics of animals fed with diets containing 5 levels of inclusion of DRB (0, 5, 10,15 and 20\%) were evaluated as well as the physiologic parameters. In the digestibility assay 12 male pigs weighing $57.3 \pm 5.6 \mathrm{~kg}$ were used. Six pigs were fed reference diets, based on corn and soybean meals, and six pigs were fed a test diet. In the performance study, 40 pigs weighing $60.8 \pm 1.98 \mathrm{~kg}$ were used. Apparent digestibility coefficients for the DM, GE, CP and CF were 53.9\%, 73.9\%, 53.3\% and 62.5\%, respectively. The values of the digestible and metabolizable energy of the DRB were 2,628 $\mathrm{kcal} / \mathrm{kg}$ and 2,623kcal/ $\mathrm{kg}$ respectively. The inclusion of up to $20 \%$ of DRB in diets did not interfere in performance, carcass characteristics and physiologic parameters of swine in termination.
\end{abstract}

Keywords: swine, alternative feed, barley, digestibility, performance

\section{INTRODUÇÃO}

A alimentação, dentre os componentes dos custos com a atividade, em granjas suinícolas estabilizadas e de ciclo completo, representa
$65 \%$ dos custos totais. Em épocas de entressafra de grãos, esse valor atinge cifras entre 70 e $75 \%$. Neste aspecto, a possibilidade de auferir lucros com a suinocultura depende do adequado planejamento da alimentação. Isso envolve a disponibilidade de ingredientes em quantidade e

Recebido em 9 de junho de 2010

Aceito em 21 de março de 2011

Email: piauidaniel@gmail.com 
qualidade adequadas a preços que viabilizem a produção.

O milho é o principal ingrediente usado na formulação de rações para suínos, assim oscilações no preço deste ingrediente influenciam diretamente no preço final da ração e, consequentemente, no preço do suíno terminado (Ferreira et al., 2004).

Diante desse cenário, cresce a busca por alternativas alimentares cujos subprodutos e resíduos industriais têm despontado na nutrição animal, principalmente pelo aparente valor nutritivo que apresentam, pela abundância de oferta, decorrente da não definição do aproveitamento desses resíduos, e pela perspectiva de redução dos custos para o produtor. Dentre os diversos alimentos alternativos, o resíduo de cervejaria vem se destacando devido à abundância da oferta, em razão do aumento da produção de cerveja no Brasil, que passou de 6,6 milhões de toneladas em 1997 para 7,3 milhões em 2007, segundo a FAO (Food..., 2009).

Os alimentos alternativos, em geral, possuem elevado teor de fibra, nutriente pouco aproveitado por monogástricos de ceco simples, em função de interferir na digestibilidade de outros nutrientes. Trata-se, ainda, de um nutriente que, nos processos metabólicos, pode proporcionar desconforto ao suíno, principalmente em épocas de altas temperaturas, devido à elevação do incremento calórico, que dificulta a dissipação de calor (Oliveira et al., 2008).

A presente pesquisa foi desenvolvida para avaliar a digestibilidade aparente da matéria seca, da proteína bruta, da energia bruta, da fibra bruta, as energias digestível e metabolizável do RDC, para suínos na fase de terminação, bem como avaliar o desempenho de suínos nesta fase, alimentados com diferentes níveis de RDC na dieta.

\section{MATERIAL E MÉTODOS}

Foram realizados dois ensaios, um de digestibilidade e outro de desempenho. No de digestibilidade, foram utilizados 12 leitões híbridos comerciais, machos, castrados, com

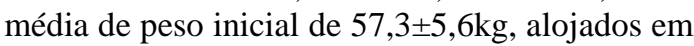
gaiolas de metabolismo. Seis receberam a dieta referência, à base de milho e farelo de soja, suplementada com minerais e vitaminas de forma a atender as exigências dos animais (Rostagno et al., 2005), e seis receberam o tratamento teste, com 30\% de substituição da dieta-referência pelo RDC. A composição calculada da dieta referência e do RDC encontra-se na Tab. 1.

O resíduo úmido de cervejaria, submetido a um processo de secagem ao sol em secador de alvenaria, durante cinco dias, foi revirado duas vezes ao dia a fim de facilitar o processo de desidratação. Em seguida, o material foi triturado para ser incorporado às dietas experimentais.

O período experimental teve duração de 16 dias, sendo seis destinados à adaptação dos animais às gaiolas de metabolismo, três para regularização do alimento no trato digestivo e sete dias para coleta. A dieta foi fornecida duas vezes ao dia, às oito e às 15 horas, com as quantidades definidas em função do peso metabólico $\left(\mathrm{PV}^{0,75}\right)$.

O método de coleta de fezes e urina foi o total, sem uso de marcador. Diariamente, as fezes foram coletadas, pesadas e homogeneizadas, e delas foram retiradas amostras correspondendo a $20 \%$ do conteúdo total, que foram acondicionadas em saco plástico e armazenadas em freezer $\left(-10^{\circ} \mathrm{C}\right)$. A urina foi coletada em baldes plásticos, acrescidos de $20 \mathrm{~mL}$ de ácido clorídrico, para evitar proliferação bacteriana e perda de nitrogênio. Após a aferição do volume, foi retirada uma alíquota de $20 \mathrm{~mL}$, que foi acondicionada em garrafas plásticas identificadas e armazenadas em freezer.

Ao fim do período experimental, as fezes foram descongeladas e homogeneizadas por gaiola, e delas foi retirada uma nova alíquota, para as análises laboratoriais, de acordo com o descrito pela AOAC (Official ..., 1990). O mesmo procedimento foi adotado para a urina. O cálculo da digestibilidade dos nutrientes foi feito conforme Matterson et al. (1965) e Gomes (1988).

No ensaio de desempenho, utilizaram-se os dados de digestibilidade do RDC, obtidos no próprio estudo, para formulação das dietas experimentais. Foram utilizados 40 leitões híbridos comerciais, 20 machos castrados e 20 fêmeas, com média de peso inicial de $60,8 \pm 1,98 \mathrm{~kg}$. 
Tabela 1. Composição centesimal da dieta referência e do resíduo desidratado de cervejaria (RDC)

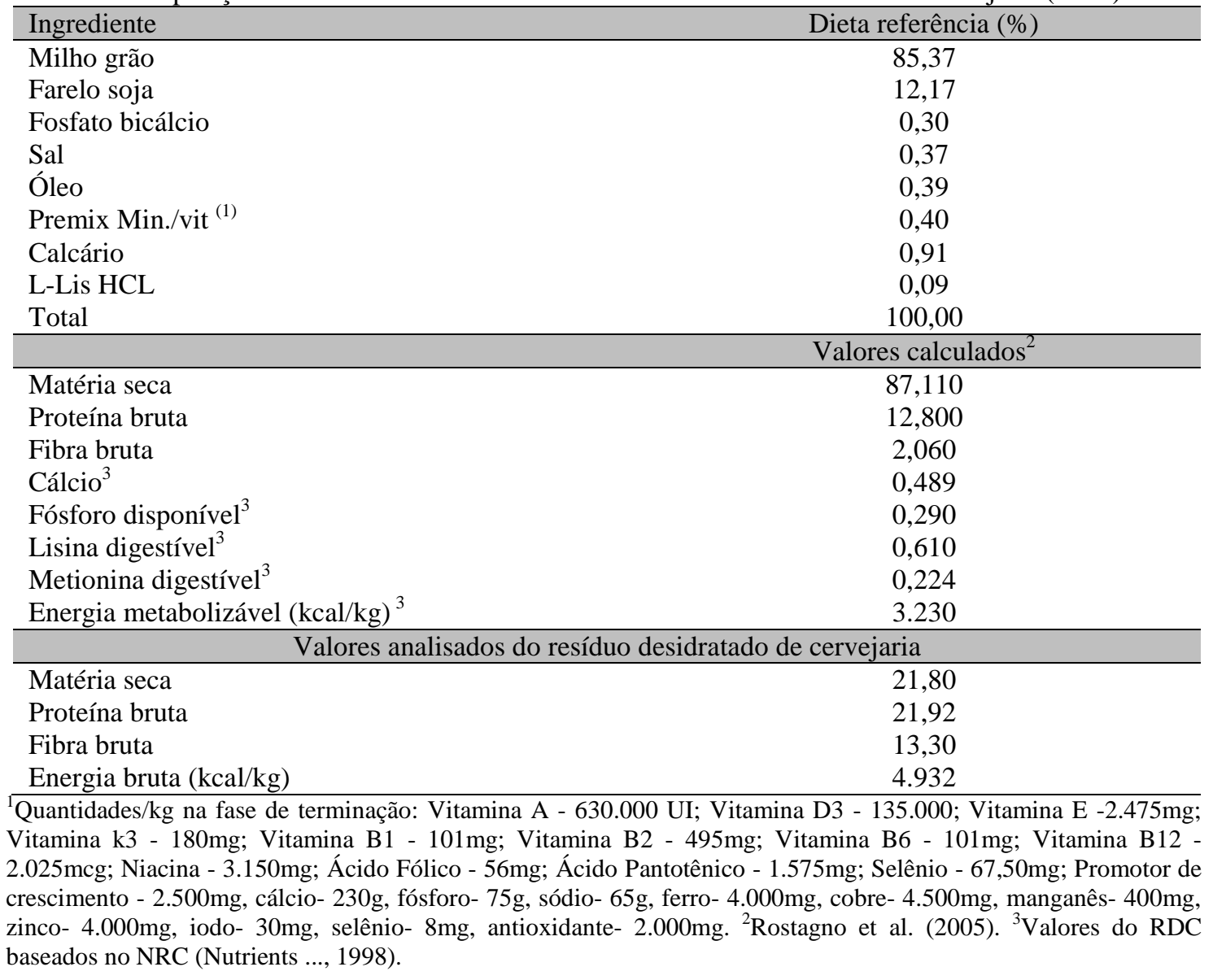

O experimento foi realizado em delineamento experimental de blocos ao acaso, baseado no peso dos animais, com cinco tratamentos e quatro repetições, constituídas de um macho e uma fêmea, alojados na mesma baia de alvenaria, com cobertura de telha cerâmica, dotada de comedouro comum de alvenaria e bebedouro automático tipo chupeta. Para os parâmetros fisiológicos, o delineamento experimental foi o de blocos ao acaso, em esquema fatorial $5 \times 2 \times 2$ (níveis de inclusão do RDC $\mathrm{x}$ sexo $\mathrm{x}$ turno do dia).

Um dos tratamentos consistiu da dieta-padrão, à base de milho e farelo de soja, suplementada com minerais e vitaminas. Os outros consistiram na inclusão de 5, 10, 15 e 20\% de RDC (Tab. 2), formulados de forma a atender às exigências dos animais (Rostagno et al., 2005). A ração era fornecida à vontade, sendo reposta duas vezes ao dia, às oito e às 15 horas, de modo a permitir que o comedouro sempre contivesse ração, porém, sem estar muito cheio, para evitar desperdícios. A temperatura retal foi aferida por meio de termômetro clínico digital, e a frequência respiratória por meio da contagem dos movimentos do flanco durante um minuto. Em ambos os ensaios, a temperatura ambiente e a umidade relativa do ar foram aferidas, diariamente, pela manhã e à tarde, por meio de termo-higrômetro digital.

Quando a média do peso dos animais da baia atingiu aproximadamente $90 \mathrm{~kg}$, estes foram abatidos, após jejum alimentar e hídrico. Em sequência, foram pesados, atordoados e sangrados, seguindo-se a higienização, evisceração, toalete e divisão da carcaça, segundo o método brasileiro de classificação de carcaças da ABCS (Método..., 1973). A área de olho de lombo foi calculada pelo método do gabarito quadriculado segundo Fialho et al. (1998). 


\section{Albuquerque et al.}

Tabela 2. Composição das dietas experimentais do ensaio de desempenho de suínos na fase de terminação com diferentes teores de inclusão do resíduo desidratado de cervejaria (RDC)

\begin{tabular}{|c|c|c|c|c|c|}
\hline \multirow[b]{2}{*}{ Ingrediente } & \multicolumn{5}{|c|}{ Teor de inclusão do RDC } \\
\hline & $0 \%$ & $5 \%$ & $10 \%$ & $15 \%$ & $20 \%$ \\
\hline Milho grão & 77,10 & 72,94 & 68,56 & 64,22 & 59,85 \\
\hline Farelo soja & 18,45 & 17,19 & 15,99 & 14,75 & 13,54 \\
\hline Fosfato bicálcico & 0,93 & 0,89 & 0,85 & 0,82 & 0,78 \\
\hline Óleo & 0,93 & 1,48 & 2,10 & 2,71 & 3,33 \\
\hline Premix Min./vit ${ }^{1}$ & 2,50 & 2,50 & 2,50 & 2,50 & 2,50 \\
\hline Resíduo desidratado cervejaria & 0,00 & 5,00 & 10,00 & 15,00 & 20,00 \\
\hline L-Lis HCL & 0,09 & 0,00 & 0,00 & 0,00 & 0,00 \\
\hline \multirow[t]{2}{*}{ Total } & 100,00 & 100,00 & 100,00 & 100,00 & 100,00 \\
\hline & \multicolumn{5}{|c|}{ Composição calculada $^{2}$} \\
\hline Proteína bruta (\%) & 12,714 & 12,713 & 12,719 & 12,713 & 12,716 \\
\hline Energia metabolizável (kcal/kg) & 3.230 & 3.230 & 3.230 & 3.230 & 3.230 \\
\hline Fibra bruta (\%) & 2,140 & 2,680 & 3,210 & 3,740 & 4,280 \\
\hline Cálcio (\%) ${ }^{3}$ & 0,884 & 0,883 & 0,881 & 0,881 & 0,879 \\
\hline Fósforo disponível (\%) ${ }^{3}$ & 0,248 & 0,249 & 0,248 & 0,249 & 0,248 \\
\hline Lisina digestível (\%) & 0,611 & 0,639 & 0,657 & 0,671 & 0,694 \\
\hline Metionina digestível (\%) ${ }^{3}$ & 0,252 & 0,272 & 0,292 & 0,301 & 0,330 \\
\hline Sódio $(\%)^{3}$ & 0,181 & 0,190 & 0,192 & 0,201 & 0,211 \\
\hline
\end{tabular}

${ }^{1}$ PREMIX Min/vit: vitamina A- 100.000UI, vitamina D3- 20.000UI, vitamina E- 440mg, vitamina K3- 60mg, vitamina. B1- 12mg, vitamina B2 100mg, vitamina B6- 20mcg, niacina- 600mg, pantot. de cálcio- 300mg, biotina, 1,5mg, colina- 6g, promotor de crescimento e eficiência alimentar $1.000 \mathrm{mg}$, cálcio- 230g, fósforo- 75g, sódio- $65 \mathrm{~g}$, ferro- $4.000 \mathrm{mg}$, cobre- $4.500 \mathrm{mg}$, manganês- $400 \mathrm{mg}$, zinco- $4.000 \mathrm{mg}$, iodo- 30mg, selênio- 8mg, antioxidante2.000mg. ${ }^{2}$ Rostagno et al. (2005). ${ }^{3}$ Valores do RDC baseados no NRC (Nutrient..., 1998).

Os resultados de desempenho foram submetidos à análise de variância e de regressão relacionando-os com os níveis de inclusão do resíduo nas dietas experimentais. Para os parâmetros fisiológicos, foi feita análise de variância e teste de comparação de médias para avaliar o efeito do sexo e do turno do dia, e análise de regressão para avaliar o efeito da inclusão do RDC nas dietas, de acordo com os procedimentos do SAS (1986).

\section{RESULTADOS E DISCUSSÃO}

Os valores médios da temperatura ambiente e da umidade relativa do ar, em função dos turnos do dia, durante o período experimental, encontramse na Tab. 3. As temperaturas médias, nos ensaios de digestibilidade e de desempenho, com valores médios de $29,57^{\circ} \mathrm{C}$ e $32,81^{\circ} \mathrm{C}$, respectivamente, estão acima da zona de conforto térmico para suínos na fase de terminação, que é de 12 a $18^{\circ} \mathrm{C}$ (Ferreira, 2000). As temperaturas no turno da tarde sempre foram mais elevadas. A umidade relativa do ar média no ensaio de digestibilidade foi de 67,2\%, enquanto a do ensaio de desempenho foi de $35,8 \%$, com o turno da manhã sempre apresentando valores mais elevados.

Tabela 3. Temperatura e umidade relativa do ar, durante o período dos ensaios de digestibilidade de nutrientes e de desempenho

\begin{tabular}{lcc}
\hline \multirow{2}{*}{ Variável } & $\begin{array}{c}\text { Ensaio } \\
\text { digestibilidade }\end{array}$ & $\begin{array}{c}\text { Ensaio } \\
\text { desempenho }\end{array}$ \\
\cline { 2 - 3 } & \multicolumn{2}{c}{ Temperatura $\left({ }^{\circ} \mathrm{C}\right)$} \\
\hline Manhã & 27,32 & 29,08 \\
Tarde & 31,83 & 36,54 \\
Média & 29,57 & 32,81 \\
\hline \multicolumn{2}{c}{ Umidade relativa do ar $(\%)$} \\
\hline Manhã & 74,80 & 44,76 \\
Tarde & 59,50 & 26,86 \\
Média & 67,15 & 35,81 \\
\hline
\end{tabular}


Os resultados relativos aos parâmetros fisiológicos, temperatura real e frequência respiratória, em função do teor de inclusão do RDC, do turno do dia e do sexo dos animais, estão apresentados na Tab. 4.

Não houve interação dos fatores teor de inclusão do RDC, sexo e turnos do dia $(\mathrm{P}>0,05)$. A inclusão do RDC nas dietas não influenciou os parâmetros fisiológicos dos suínos na fase de terminação $(\mathrm{P}>0,05)$. No entanto, o turno do dia e o sexo dos animais indicaram efeito na temperatura retal, com valores mais elevados para as medidas realizadas à tarde e com os machos $(\mathrm{P}<0,05)$. As diferenças observadas, provavelmente, são devido à maior capacidade dos machos castrados de acumularem gordura subcutânea, o que dificulta a dissipação de calor.

Tabela 4. Parâmetros fisiológicos de suínos na fase de terminação nos períodos da manhã e tarde alimentados com diferentes níveis de resíduo desidratado de cervejaria (RDC)

\begin{tabular}{|c|c|c|c|c|c|}
\hline \multirow{3}{*}{$\begin{array}{l}\text { Teor de inclusão } \\
\text { do RDC }\end{array}$} & \multicolumn{5}{|c|}{ Temperatura retal $\left({ }^{\circ} \mathrm{C}\right)$} \\
\hline & \multicolumn{2}{|c|}{ Macho } & \multicolumn{2}{|c|}{ Fêmea } & \multirow[t]{2}{*}{ Média $^{1}$} \\
\hline & Manhã & Tarde & Manhã & Tarde & \\
\hline $0 \%$ & 39,51 & 39,77 & 39,24 & 39,49 & 39,48 \\
\hline $5 \%$ & 39,95 & 40,06 & 39,28 & 39,70 & 39,75 \\
\hline $10 \%$ & 39,28 & 39,64 & 39,22 & 39,56 & 39,42 \\
\hline $15 \%$ & 39,21 & 39,26 & 39,03 & 39,42 & 39,23 \\
\hline $20 \%$ & 39,62 & 39,80 & 39,64 & 39,49 & 39,64 \\
\hline Média geral por sexo & \multicolumn{2}{|c|}{$39,61 a$} & \multicolumn{2}{|c|}{$39,41 b$} & \\
\hline Média geral por turno & $39,39 b$ & \multicolumn{3}{|l|}{$39,61 \mathrm{a}$} & \\
\hline CV (\%) & & & 1,11 & & \\
\hline \multicolumn{6}{|c|}{ Frequência respiratória (ciclos/minuto) } \\
\hline $0 \%$ & 47,44 & 67,33 & 53,83 & 83,83 & 63,93 \\
\hline $5 \%$ & 47,58 & 70,83 & 55,58 & 100,29 & 68,57 \\
\hline $10 \%$ & 63,58 & 88,25 & 52,58 & 83,00 & 71,85 \\
\hline $15 \%$ & 57,75 & 84,42 & 52,92 & 89,92 & 71,25 \\
\hline $20 \%$ & 53,75 & 74,83 & 48,08 & 64,08 & 60,19 \\
\hline Média geral por sexo & \multicolumn{2}{|c|}{$66,01 \mathrm{a}$} & \multicolumn{2}{|c|}{$68,41 a$} & \\
\hline Média geral por turno & $53,46 b$ & $81,02 a$ & & & \\
\hline CV (\%) & & & 32,66 & & \\
\hline
\end{tabular}

${ }^{1}$ Não houve efeito linear e quadrático ( $\left.\mathrm{P}>0,05\right)$.

Médias, para um mesmo fator, seguidas de letras distintas, diferem entre si pelo teste Duncan $(\mathrm{P}>0,05)$.

Com relação à frequência respiratória, no turno da tarde, em decorrência de as temperaturas ambientais serem mais elevadas, os leitões, na tentativa de dissiparem calor para o ambiente, aumentaram a frequência, com valores acima da faixa dos 32 e 58 ciclos/minutos, considerados normais para espécie (Reece, 1996), embora a temperatura retal permanecesse dentro da faixa normal de 37,9 a $39,9^{\circ} \mathrm{C}$ (Ferreira, 2000).

Os coeficientes de digestibilidade e de metabolizabilidade da matéria seca, proteína bruta, energia bruta e da fibra bruta encontram-se na Tab. 5. Os resultados revelam que a proteína bruta do RDC foi bem aproveitada pelos leitões em terminação, sendo excretados nas fezes 26,1\% do total consumido. Esta constatação, em parte, pode ser explicada em razão de a fração fibrosa ter sido bem digerida, mesmo com o teor de $13,3 \%$ de fibra bruta, pois a fibra em geral promove diminuição da absorção dos nutrientes (Li et al., 1994) e aumenta a perda de aminoácidos endógenos.

Os coeficientes de digestibilidade e de metabolizabilidade da matéria seca foram considerados baixos, tendo reflexos nos valores dos coeficientes de digestibilidade e de metabolizabilidade da energia bruta. Nesse contexto, os valores das energias digestível e metabolizável do RDC foram, respectivamente, de 2.628 e $2.623 \mathrm{kcal} / \mathrm{kg}$, estando em consonância com o valor observado por Kornegay (1973), que, em trabalho com suínos na fase de terminação, obteve coeficientes de energias digestível e metabolizável, respectivamente, de 
$52,3 \%$ e 49,4\%, e energias digestível e metabolizável, respectivamente, de 2.650, $2.500 \mathrm{kcal} / \mathrm{kg}$.

Estes resultados podem ser justificados em função de, na fase de terminação, os suínos apresentarem dificuldades de perder calor para o ambiente, o que pode ter afetado inclusive o consumo de ração (Jensen, 1991; Kiefer et al., 2009). Andersson e Jónasson (1996) relataram que se houver desconforto térmico, com aumento da temperatura corporal, os termorreceptores acionam os mecanismos responsáveis pela perda de calor corpóreo extra com o aumento do ritmo respiratório e vasodilatação periférica.

O balanço de nitrogênio, tanto para a dieta referência como para a dieta teste, foi positivo (Tab. 6), com valores, respectivamente, de 33,20 e 32,88g de N/dia, caracterizando que a proteína do RDC é bem aproveitada pelos suínos na fase de terminação.

Tabela 5. Coeficientes de digestibilidade e metabolizabilidade da matéria seca, da proteína bruta, da energia bruta e da fibra bruta do resíduo desidratado de cervejaria (RDC)

\begin{tabular}{lcc}
\hline Variável & $\begin{array}{c}\text { Coeficiente de digestibilidade } \\
(\%)\end{array}$ & $\begin{array}{c}\text { Coeficiente de metabolizabilidade } \\
(\%)\end{array}$ \\
\hline Matéria seca & 53,90 & 48,97 \\
Proteína bruta & 73,87 & 73,52 \\
Energia bruta & 53,28 & 53,19 \\
Fibra bruta & 62,51 & - \\
\hline
\end{tabular}

Tabela 6. Valores do balanço de nitrogênio das dietas controle e teste, e da energia digestível e metabolizável do resíduo desidratado de cervejaria para suínos em terminação

\begin{tabular}{lc}
\hline Variável & Valor \\
\hline Balanço de nitrogênio da dieta referência (g/dia) & 33,20 \\
Balanço de nitrogênio da dieta teste (g/dia) & 32,88 \\
Energia digestível do resíduo desidratado de cervejaria $(\mathrm{kcal} / \mathrm{kg})$ & 2.628 \\
Energia metabolizável do resíduo desidratado de cervejaria $(\mathrm{kcal} / \mathrm{kg})$ & 2.623 \\
\hline
\end{tabular}

Os resultados de desempenho e peso da carcaça e dos principais cortes, de acordo com os níveis de inclusão do RDC, encontram-se na Tab. 7. Não houve efeito $(\mathrm{P}>0,05)$ dos teores de inclusão do RDC sobre os parâmetros de desempenho, até 20\% de inclusão do ingrediente. Este resultado difere do relatado por Farias et al. (2008), os quais destacaram que a inclusão de fibra na dieta de suínos, geralmente, diminui o ganho diário de peso, o consumo diário de ração e piora a conversão alimentar. Bastos et al. (2002) observaram que não houve alteração dos parâmetros de desempenho com a inclusão do alimento teste, no caso o milheto. Esses autores concluíram que o aumento gradativo do teor de óleo nas dietas teste contribuiu para o resultado. Segundo Donzele et al.(1998), os lipídios atuam provocando efeito inibitório do esvaziamento do trato digestivo, o que permite maior tempo para a absorção dos nutrientes.

Quanto ao peso e às medidas de carcaça e peso dos principais cortes, órgãos e vísceras, também não houve interferência das dietas experimentais $(\mathrm{P}>0,05)$ sobre essas variáveis. Os valores obtidos foram menores que os encontrados, por exemplo, por Dutra Jr. et al. (2001). A inclusão do RDC não diminuiu a espessura de toucinho, provavelmente em decorrência do aumento do teor de óleo das dietas com teores mais elevados do RDC. O peso dos órgãos internos, também, não foi influenciado pela proporção de inclusão do RDC $(\mathrm{P}>0,05)$.

Os resultados de rendimento da carcaça e dos principais cortes (Tab. 8) mostraram que os níveis de inclusão do RDC não interferiram em nenhuma das variáveis estudadas $(\mathrm{P}>0,05)$. Estes resultados são similares aos encontrados por Vieira et al. (2006), que, ao trabalharem com o resíduo de cervejaria para suínos em crescimento e dieta normal na fase de terminação, não observaram efeito da inclusão do resíduo de cervejaria no peso do trato gastrintestinal, do fígado, do estômago e das vísceras, nem da carcaça e dos principais cortes. 
Tabela 7. Ganho diário de peso (GDP), consumo diário de ração (CDR), conversão alimentar (CA), pesos da carcaça e dos principais cortes, comprimento de carcaça (CCARC), área de olho de lombo (AOL) e média da espessura de toucinho (ESPT) de suínos na fase de terminação, alimentados com diferentes teores de resíduo desidratado de cervejaria (RDC)

\begin{tabular}{lcccccc}
\hline \multirow{2}{*}{ Variável } & \multicolumn{7}{c}{ Teor de inclusão do RDC } & \multirow{2}{*}{ CV (\%) } \\
\cline { 2 - 5 } & $0 \%$ & $5 \%$ & $10 \%$ & $15 \%$ & $20 \%$ & \\
\hline GDP, kg & 0,762 & 0,776 & 0,828 & 0,874 & 0,735 & 17,94 \\
CDR, kg & 2,30 & 2,43 & 2,55 & 2,65 & 2,26 & 21,55 \\
CA & 3,02 & 3,16 & 3,08 & 3,01 & 3,06 & 11,03 \\
Peso vivo (kg) & 88,95 & 89,25 & 94,00 & 92,50 & 89,40 & 6,68 \\
Carcaça quente (kg) & 68,83 & 68,65 & 74,18 & 72,98 & 70,83 & 5,87 \\
Pernil (kg) & 9,46 & 9,48 & 10,28 & 10,30 & 9,86 & 5,27 \\
Paleta (kg) & 5,37 & 5,28 & 5,57 & 5,49 & 5,59 & 5,61 \\
Lombo (kg) & 5,81 & 5,80 & 6,14 & 6,30 & 6,41 & 12,37 \\
Barriga (kg) & 4,96 & 4,67 & 5,33 & 4,67 & 4,85 & 9,66 \\
Dianteiro (kg) & 4,23 & 4,32 & 4,53 & 5,16 & 4,26 & 11,46 \\
CCARC (cm) & 94,62 & 96,38 & 96,00 & 97,12 & 97,75 & 3,21 \\
AOL (cm $\left.{ }^{2}\right)$ & 31,62 & 28,58 & 33,91 & 35,80 & 33,91 & 16,83 \\
ESPT (mm) & 26,92 & 26,00 & 28,17 & 24,48 & 26,08 & 16,95 \\
\hline
\end{tabular}

Não houve efeito da inclusão do RDC sobre as variáveis $(\mathrm{P}>0,05)$.

Tabela 8. Rendimentos de carcaça (RCARC), pernil (RPER), paleta (RPAL), lombo (RLOMB), barriga (RBAR), dianteiro (RDIAN), peso dos órgãos internos e do trato gastrintestinal cheio (TGI) e vazio (TGV) de suínos alimentados com diferentes teores de inclusão do resíduo desidratado de cervejaria (RDC)

\begin{tabular}{lcccccc}
\hline \multirow{2}{*}{ Variável } & \multicolumn{5}{c}{ Teor de inclusão do RDC } & CV (\%) \\
\cline { 2 - 5 } & $0 \%$ & $5 \%$ & $10 \%$ & $15 \%$ & $20 \%$ & \\
\hline RCARC (\%) & 77,47 & 76,97 & 79,00 & 78,92 & 79,24 & 3,06 \\
RPER (\%) & 27,58 & 27,58 & 27,72 & 28,21 & 27,84 & 3,38 \\
RPAL (\%) & 15,65 & 15,40 & 15,01 & 15,04 & 15,79 & 5,67 \\
RLOMB (\%) & 16,78 & 16,83 & 16,55 & 17,25 & 18,10 & 8,06 \\
RBAR (\%) & 14,35 & 13,58 & 14,36 & 12,79 & 13,67 & 5,50 \\
RDIAN (\%) & 12,25 & 13,58 & 12,19 & 14,15 & 12,00 & 9,70 \\
Fígado (kg) & 1,67 & 1,85 & 1,69 & 1,58 & 1,73 & 15,03 \\
Baço (kg) & 0,15 & 0,12 & 0,15 & 0,13 & 0,14 & 14,00 \\
Pulmões (kg) & 1,00 & 1,13 & 1,11 & 0,98 & 1,07 & 32,11 \\
Rins (kg) & 0,28 & 0,31 & 0,34 & 0,29 & 0,28 & 12,03 \\
Coração (kg) & 0,33 & 0,39 & 0,37 & 0,34 & 0,34 & 15,51 \\
TGI(kg) & 7,74 & 9,21 & 7,90 & 8,24 & 8,53 & 17,19 \\
TGV (kg) & 3,86 & 4,02 & 3,50 & 4,11 & 4,26 & 22,21 \\
\hline
\end{tabular}

Não houve efeito da inclusão do RDC sobre as variáveis (P>0,05).

\section{CONCLUSÕES}

O resíduo desidratado de cervejaria possui valores de energias digestível e metabolizável, respectivamente, de 2.628 e $2.623 \mathrm{kcal} / \mathrm{kg}$, e pode ser incluído em até $20 \%$ nas dietas de suínos em terminação, desde que as dietas sejam devidamente balanceadas, sem que haja prejuízo do desempenho.

\section{REFERÊNCIAS BIBLIOGRÁFICAS}

ANDERSSON, B.E.; JÓNASSON, H. Regulação da temperatura e fisiologia. In: SWENSON, M.J.; REECE, W.O. (Org.). Dukes fisiologia dos animais domésticos. 11.ed. Rio de Janeiro: Guanabara Koogan, 1996. p. 805-813.

BASTOS, A.O.; LANDELL FILHO, L.C.; PASSIPIERI, M. et al. Diferentes níveis de grão de milheto (Pennisetum glaucum (L.) R. Brown) na alimentação de suínos. Rev. Bras. Zootec., v.31, p.1753-1760, 2002. 
DONZELE, J.L.; SILVA, F.C.O.; FERREIRA, A.S. et al. Digestibilidade e metabolizabilidade de energia de rações com diferentes níveis de óleo de soja para suínos. Rev. Bras. Zootec, v.27, p.922-927, 1998.

DUTRA Jr., W.M.; FERREIRA, A.L.; TAROUCO, J.U. et al. Estimativa de rendimento de cortes comerciais e de tecidos de suínos em diferentes pesos de abate pela técnica de ultrassonografia em tempo real. Rev. Bras. Zootec., v.33, p. 1243-1250, 2001.

FARIAS, L.A.; LOPES, J.B.; FIGUEIRÊDO, A.V. et al. Pseudofruto do cajueiro (Anacardium occidentale L.) para suínos em crescimento: Metabolismo de nutrientes e desempenho. Cienc. Anim. Bras., v.9, p.100-109, 2008.

FERREIRA, R.A. Efeitos do clima sobre a nutrição de suínos. In: ENCONTROS TÉCNICOS ABRAVES. 11., 2000, Chapecó. Anais... Concórdia: EMBRAPA Suínos e Aves, 2000.

FERREIRA, R.A.; FIALHO, E.T.; LIMA, J.A.F. Criação técnica de suínos. Lavras: Universidade Federal de Lavras, 2004. 59p.

FIALHO, E.T.; OLIVIERA, A.I.; GOMES E.T. et al. Influência de planos de nutrição sobre as características de carcaça de suínos de diferentes genótipos abatidos entre 80 e $120 \mathrm{~kg}$. Rev. Bras. Zootec, v.27, p.1140-1146, 1998.

\section{FOOD AND AGRICULTURE ORGANIZATION OF THE UNITED NATIONS - FAO (2009). Statistics Division. Disponível em: <http://faostat.fao.org> Acessado em: 08 jan. 2009.}

GOMES, P.C. Exigência nutricional de fósforo e sua disponibilidade em alguns alimentos para suínos de diferentes idades. 1988. 163f. Tese (Doutorado em Nutrição de Monogástricos)Universidade Federal de Viçosa, Viçosa, MG.

JENSEN, A.H. Environment and management factors that influence swine nutrition. In: MILLER, E.R.; ULLREY, E.D.; LEWIS, A.J. (Org.). Swine nutrition. London: ButterworthHeinemann, 1991. p.387-399.
KIEFER, C.; MEIGNEN, B.C.G.; SANCHES, J.F. et al. Resposta de suínos em crescimento mantidos em diferentes temperaturas. Arch. Zootec. v.58, p.55-64, 2009.

KORNEGAY, E.T. Digestible and metabolizable energy and protein utilization values of brewers dried by-products for swine. J. Anim. Sci., v.37, p.479-483, 1973.

LI, S.; SAUER, W.C.; HARDIN, R.T. Effect of dietary fiber level on amino acid digestibility in young pigs. Can. J. Anim. Sci., v.74, p.327-333, 1994.

MATTERSON, L.D.; POTTER, L.M.; STUTZ, M.W. et al. The metabolizable energy of feed ingredients for chickens. Res. Rep., v.7, p.3-11, 1965.

MÉTODO brasileiro de classificação de carcaças. Estrela: ABCS (Publicação Técnica 2), 1973. 17p.

OFFICIAL methods of analysis. 15. ed. Washington DC: AOAC, 1990. 1141p.

OLIVEIRA, E.R.A.; SILVA, J.H.V.; COELHO, M.S. et al. Alimentos fibrosos para suínos. Publ. Med. Vet. Zootec., v.2, 2008.

REECE, W.O. Respiração nos mamíferos. In: SWENSON, M.J. e REECE, W.O. (Org.). Dukes fisiologia dos animais domésticos. 11.ed. Rio de Janeiro: Guanabara Koogan, 1996. p. 241-276.

ROSTAGNO, H.S.; ALBINO. L.F.T.; DONZELE, J.L. et al. Tabelas Brasileiras para aves e suínos: Composição de alimentos e exigências nutricionais. Viçosa: Imprensa Universitária, 2005. 186p.

VIEIRA, A.A.; BRAZ, J.M.; COSTA, A.D. Desempenho de suínos em crescimento alimentados com dietas contendo bagaço de cevada. In: CONGRESSO BRASILEIRO DE ZOOTECNIA, 16., 2006, Recife. Anais... Recife: SBZ, 2006. CD-ROM. 